\title{
The kinetics and mechanical study of borided iron aluminide $(\mathrm{FeAl})$
}

\author{
M. Usta*, E. Ekmekçiler \\ Department of Materials Science and Engineering, Gebze Institute of Technology, Gebze, Kocaeli 41400, Turkey
}

Received 8 March 2010, received in revised form 7 April 2010, accepted 8 April 2010

\begin{abstract}
The kinetics of formation of iron borides by boronizing of FeAl was studied. FeAl samples were exposed to boronizing process in a solid medium at $875^{\circ} \mathrm{C}, 940{ }^{\circ} \mathrm{C}, 1040^{\circ} \mathrm{C}$ for 2,4 and $8 \mathrm{~h}$. The characterization and morphology of boride layers were studied by XRD analysis and metallographic technique. The results showed that increasing boronizing time and temperature led to thicker boride layers. The thickness of boride layers ranged from 8 to $60 \mu \mathrm{m}$ with changing boronizing temperatures and times. Depending on treatment temperatures and times, the hardness of the boride layers ranged from 1290 to $1500 \mathrm{HV}$, while the hardness of the substrate ranged from 340 to $490 \mathrm{HV}$. XRD analysis revealed that FeB phase was a major phase at all temperatures. However, $\mathrm{Fe}_{2} \mathrm{~B}$ phase was detected as a minor phase at only $1040^{\circ} \mathrm{C}$ for $8 \mathrm{~h}$. The formation of iron borides followed a parabolic growth rate law, showing a diffusion-controlled process.
\end{abstract}

K e y w or d s: boronizing, iron aluminides, borides, kinetics, diffusion-controlled

\section{Introduction}

The B2 type intermetallic compounds composed of the iron group transition metal and aluminum, e.g. $\mathrm{NiAl}, \mathrm{CoAl}$ and $\mathrm{FeAl}$, received much attention as high temperature materials $[1,2]$. Among these, $\mathrm{Fe}_{3} \mathrm{Al}$ and $\mathrm{FeAl}$ intermetallics were most widely studied because of their low cost, relatively low density as compared with Co and Ni-base alloys, good wear resistance, ease of fabrication and excellent resistance to oxidation and corrosion. These advantages make the iron aluminides very promising candidate for high-temperature applications, such as furnace fixtures, heat exchanger piping, turbine blades in jet engines, automobile and other industrial valve components, catalytic converter substrate and component for molten salt applications $[1$, $3,4]$. Many studies have been done to improve their mechanical properties throughout control of microstructure and alloy composition $[3,5,6]$. In addition, the boriding of $\mathrm{FeAl}$ was studied to enhance its mechanical behavior $[7,8]$.

The boronizing is a thermochemical diffusion surface treatment in which boron atoms diffuse into the surface of the work piece to form hard borides with the base materials [9-21]. Boronizing is a prominent choice for a wide range of tribological applications where the control of friction and wear is of primary concern [22]. Boronizing, a thermochemical diffusion treatment, can be applied to a wide range of steel alloys including carbon steel, low alloy steel, tool steel and stainless steel. In addition, materials such as nickel-base alloys, cobalt-base alloys, molybdenum and titanium can be boronized to obtain very high hardness and wear resistance on their surfaces [9-22]. The strong covalent bonding in most transition metal diborides is largely responsible for their high melting points, high mechanical strength, elastic modulus, hardness values and chemical inertness.

The boronizing of $\mathrm{FeAl}$ at $940{ }^{\circ} \mathrm{C}$ was achieved in our previous study [7]. In the previous study, the kinetics of the boronizing of the FeAl was not studied. Moreover, there is only one research on the kinetics of boronizing for $\mathrm{Fe}_{72} \mathrm{Al}_{28}\left(\mathrm{Fe}_{3} \mathrm{Al}\right)$ in liquid boronizing medium [8]. In addition, the $\mathrm{Fe}_{3} \mathrm{Al}$ and the $\mathrm{FeAl}$ have different compositions. Since the kinetics study of boronizing on the $\mathrm{FeAl}$ is missing in the literature,

*Corresponding author: tel.: 90-262-6051782; fax: + 90-262-6538490; e-mail address: ustam@gyte.edu.tr 
Table 1. The chemical composition of FeAl used in the study (wt.\%)

\begin{tabular}{cc}
\hline Elements & Chemical composition (in wt.\%) \\
\hline $\mathrm{Fe}$ & 75.38 \\
$\mathrm{Cr}$ & 0.003 \\
$\mathrm{Si}$ & 0.009 \\
$\mathrm{Mn}$ & $\leq 0.003$ \\
$\mathrm{Ni}$ & $\leq 0.003$ \\
$\mathrm{C}$ & 0.005 \\
$\mathrm{O}$ & $\leq 0.001$ \\
$\mathrm{~N}$ & $\leq 0.001$ \\
$\mathrm{~S}$ & 0.003 \\
$\mathrm{Al}$ & Bal. \\
\hline
\end{tabular}

the present paper focuses on the kinetics of boronizing on $\mathrm{FeAl}$ at $875^{\circ} \mathrm{C}, 940^{\circ} \mathrm{C}, 1040^{\circ} \mathrm{C}$ for 2,4 and $8 \mathrm{~h}$. In this context, the aim of the present paper is to study the kinetics of boronizing on the $\mathrm{FeAl}$ and compare the kinetics of $\mathrm{FeAl}$ with $\mathrm{Fe}_{3} \mathrm{Al}$.

\section{Experimental procedure}

Substrate material used for this study was iron aluminide $(\mathrm{FeAl})$ that had a rectangular shape of $7 \mathrm{~mm} \times 2 \mathrm{~mm} \times 10 \mathrm{~mm}$. The chemical composition of $\mathrm{FeAl}$ is given in Table 1. Before boronizing, the samples to be coated were ground using 500 grid polishing paper to obtain a good surface finish.

Boronizing was performed in a solid medium by using Ekabor powders that had grain sizes of less than $850 \mu \mathrm{m}$ and had a nominal composition of $90 \% \mathrm{SiC}$ as a diluent to control the boriding potential of the medium, and a reducing agent, $5 \% \mathrm{~B}_{4} \mathrm{C}$ as a donor, and $5 \% \mathrm{KBF}_{4}$ as an activator. The test materials to be boronized were placed in a contact with Ekabor powders in a stainless steel crucible of $5 \mathrm{~cm}$ in diameter and $8 \mathrm{~cm}$ in height and then transferred to an electrical resistance furnace. The test materials were heated to temperature of $875^{\circ} \mathrm{C}, 940^{\circ} \mathrm{C}$ and $1040^{\circ} \mathrm{C}$ under atmospheric pressure and held in the furnace for 2,4 and $8 \mathrm{~h}$. The process was followed by cooling in air. Then the coated samples were cleaned in hot water.

The morphology and types of boride formed on the surface of $\mathrm{FeAl}$ substrate were examined by means of conventional metallographic technique. Rigaku X-ray diffractometer with a $\mathrm{Cu} \mathrm{K} \alpha$ radiation source of a wavelength of $1.504 \AA$ over a $2 \theta$ range from $20^{\circ}$ to $90^{\circ}$ was employed for a characterization of the boride. Philips field emission scanning electron microscope (SEM) was used to study the morphology of the boride.

The microhardness of boride formed on the surface of $\mathrm{FeAl}$ and the hardness of the borided $\mathrm{FeAl}$ from the surface to the interior were measured by Instron microhardness tester fitted with a Vickers diamond indenter and a load of $50 \mathrm{~g}$. Before the measurements, samples were prepared by using conventional metallographic techniques.

\section{Experimental results}

\subsection{Microstructure and morphology of borided $\mathrm{FeAl}$}

SEM studies showed that outer layer iron borides had a columnar grain structure appearing as saw-tooth morphology elongated in the diffusion direction. Figure 1 shows SEM examinations of the boride formed at $875^{\circ} \mathrm{C}, 940{ }^{\circ} \mathrm{C}$ and $1040^{\circ} \mathrm{C}$ for $2 \mathrm{~h}$. It is noted that three regions are marked on the micrographs as "1", "2" and "3". They are identified as follows: (1) a layer having boride ( $\mathrm{FeB}$ or $\left.\mathrm{FeB} / \mathrm{Fe}_{2} \mathrm{~B}\right),(2)$ a diffusion/transition zone, and (3) a substrate material. It is difficult to separate region " 2 " from region " 3 " in Fig. 1a-c; the microhardness indentation mark in Fig. 2 makes easier to distinguish them.

\subsection{Hardness of boride layer}

The hardness of iron borides formed on $\mathrm{FeAl}$ was between 1290 to $1500 \mathrm{HV}$, whereas the hardness of the substrate ranged from 340 to $490 \mathrm{HV}$. The results showed that the hardness of boride formed on the surface of borided $\mathrm{FeAl}$ was much higher than of the substrate due to a presence of hard $\mathrm{FeB}$ or $\mathrm{FeB} / \mathrm{Fe}_{2} \mathrm{~B}$. This is represented in Fig. 2.

Figure 2 shows the hardness variation from the surface to the interior. It is clearly seen that distribution of the hardness in the material changes from the surface to the interior in Figs. 2 and 3.

Figure 3 also shows the changes in hardness values from the surface to the interior of the borided iron aluminide. The hardness decreases with increasing distance from the surface. Due to the anisotropy of the layers the indentation marks are not symmetrical. Therefore, at least five hardness measurements were performed at different locations of the coating and their average values were given in Fig. 3. Figure 4 reveals the X-ray diffraction patterns of the borided iron aluminide.

X-ray study shows the presence of FeB. Examining X-ray analyses, $\mathrm{FeB}$ phase was observed but $\mathrm{Fe}_{2} \mathrm{~B}$ phase was not detected except boriding at $1040^{\circ} \mathrm{C}$ for $8 \mathrm{~h}$ shown in Fig. 4. Moreover, minor $\mathrm{Fe}_{2} \mathrm{O}_{3}$ phase is found with $\mathrm{Fe}_{2} \mathrm{~B}$ at that temperature.

Figure 5 shows square of thickness of the boride layer vs. time of boriding. As it can be seen in Fig. 5, an increase in boriding time and temperature results in a thicker coating layer. 

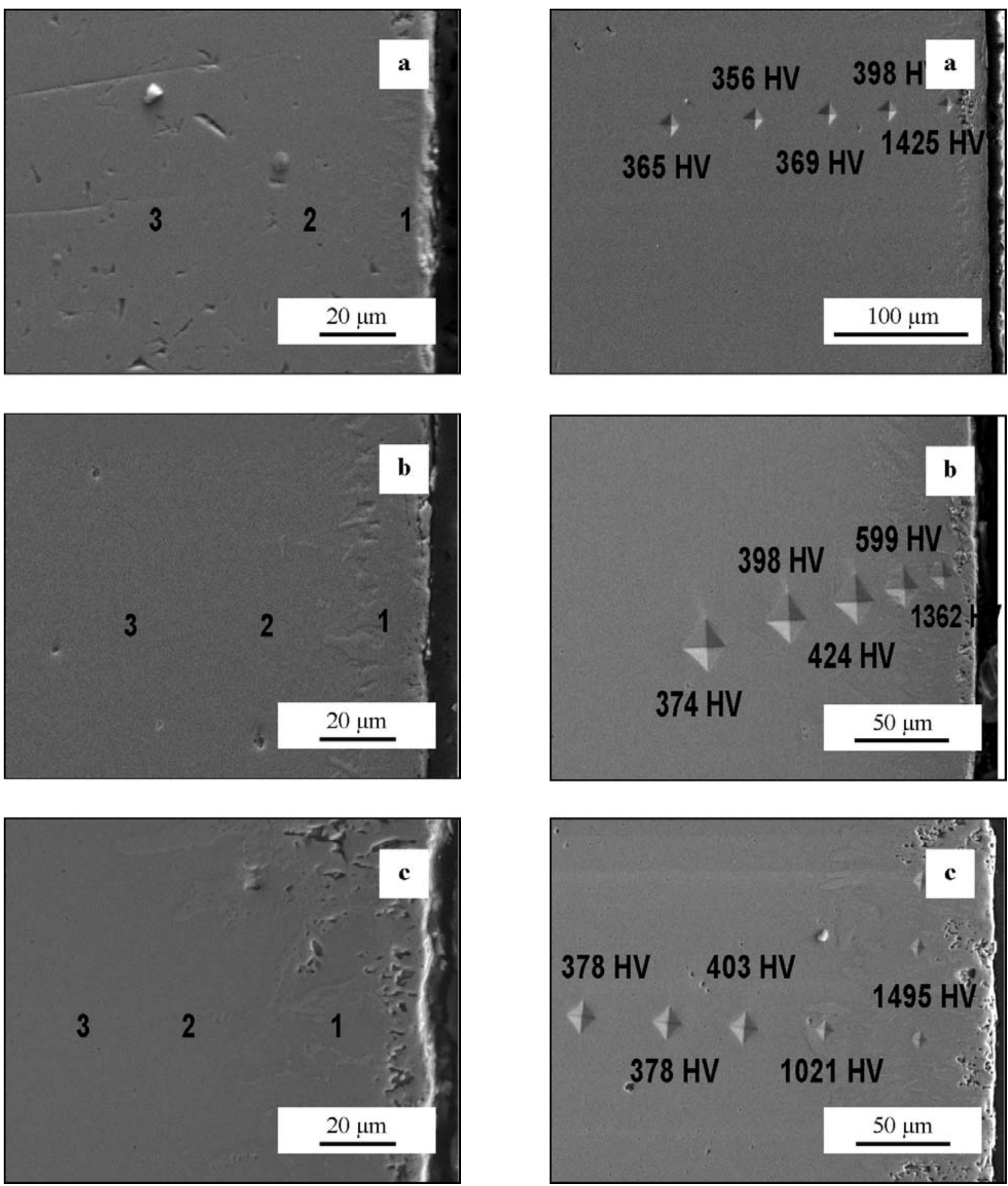

Fig. 1. SEM images of FeAl borided at (a) $875^{\circ} \mathrm{C}$, (b) $940^{\circ} \mathrm{C}$, (c) $1040^{\circ} \mathrm{C}$ for $2 \mathrm{~h}$.

Fig. 2. Hardness variation of $\mathrm{FeAl}$ borided at (a) $875^{\circ} \mathrm{C}$, (b) $940^{\circ} \mathrm{C}$, (c) $1040^{\circ} \mathrm{C}$ for $8 \mathrm{~h}$.

\subsection{Analysis of the growth kinetics}

The Fick's laws establish the concentrations of boron in the $\mathrm{FeB}$ and $\mathrm{Fe}_{2} \mathrm{~B}$. The diffusion coefficient depends on the temperature of the process (according

to the Arrhenius equation), the diffused boron concentration on the surface and the content of alloy elements in the substrate. Fick's laws were used to determine the concentration of boron into $\mathrm{FeB} / \mathrm{Fe}_{2} \mathrm{~B}$ layer that grows following a parabolic law $[18,21,22]$ : 


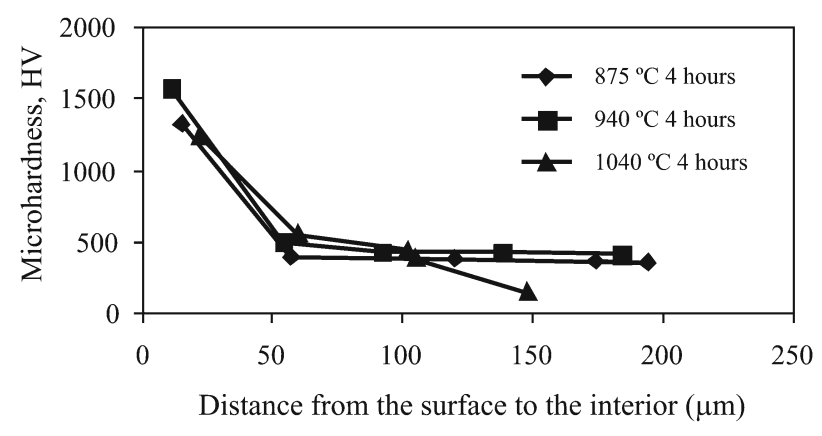

Fig. 3. Microhardness vs. distance from the surface to the interior of $\mathrm{FeAl}$ borided at $875^{\circ} \mathrm{C}, 940^{\circ} \mathrm{C}, 1040^{\circ} \mathrm{C}$ for $4 \mathrm{~h}$.

$$
x^{2}=k t
$$

where $x$ is the depth of boride layer, $t$ is time of process, $k$ is the growth rate constant, which depends on boriding temperature and is calculated from the slopes of the $x^{2}$ versus treatment time graph.

The relationship between the diffusion coefficients (growth rate constant), $k\left(\mathrm{~m}^{2} \mathrm{~s}^{-1}\right)$, activation energy, $Q\left(\mathrm{~J} \mathrm{~mol}^{-1}\right)$ and the process temperature $T$ in Kelvin can be expressed as an Arrhenius-type equation [18, $21,22]$ :

$$
k=k_{0} \cdot \mathrm{e}^{-Q / R T}
$$
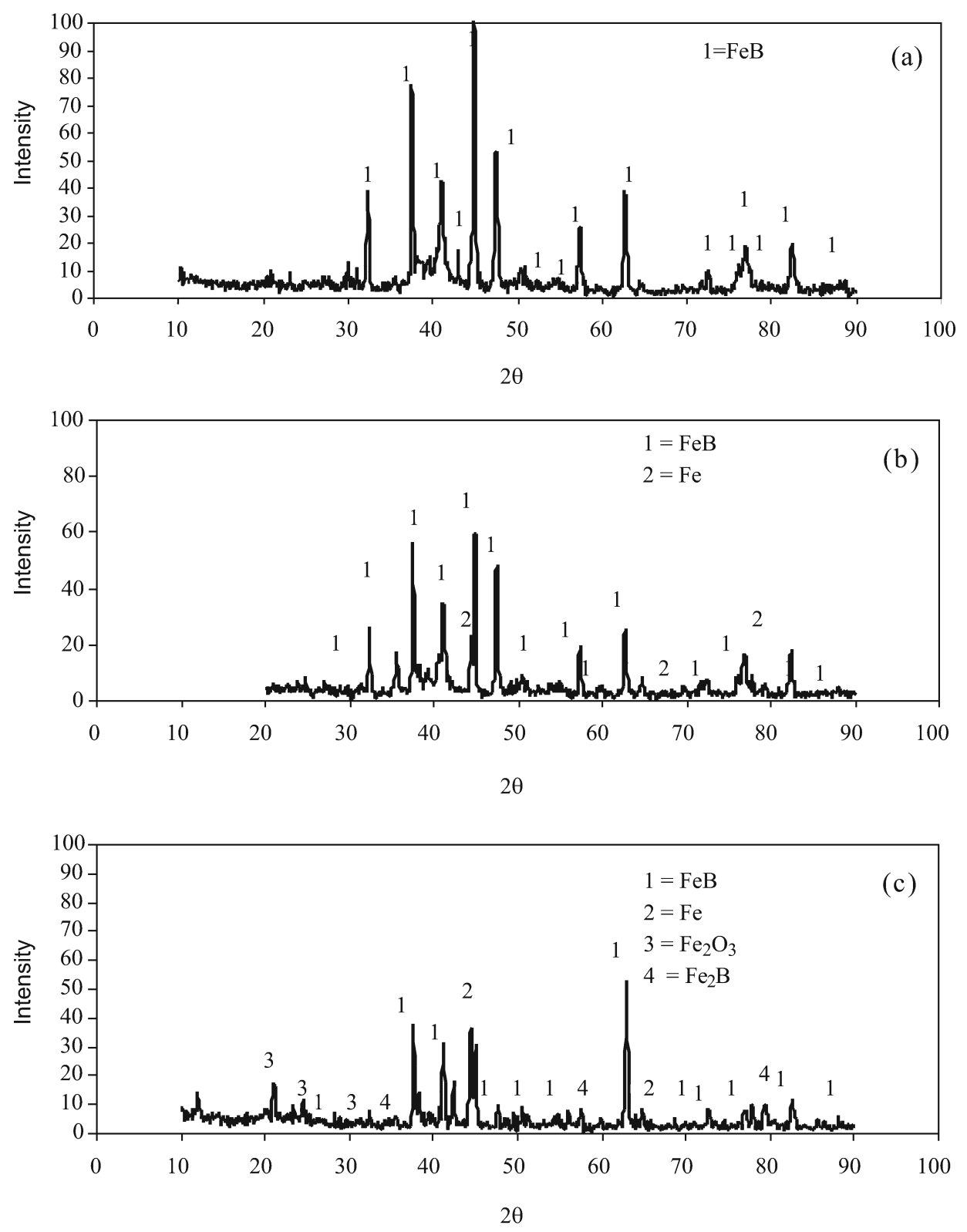

Fig. 4. X-ray diffraction patterns of the sample borided at (a) $875^{\circ} \mathrm{C}$, (b) $940{ }^{\circ} \mathrm{C}$, (c) $1040^{\circ} \mathrm{C}$ for $8 \mathrm{~h}$. 


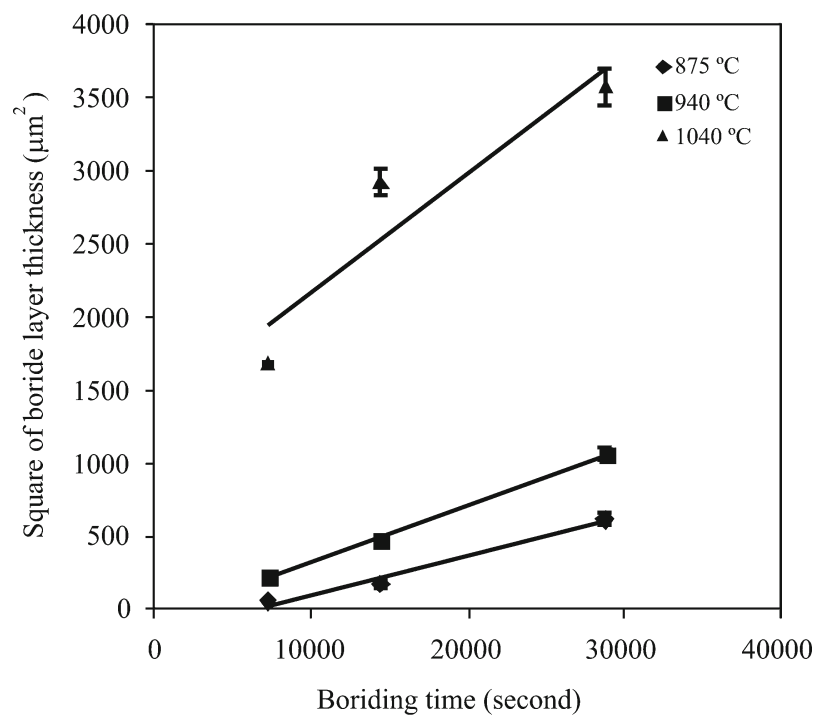

Fig. 5. The square of thickness of the boride layer vs. time of boriding plot, showing the increased boride layer with increasing time and temperature.

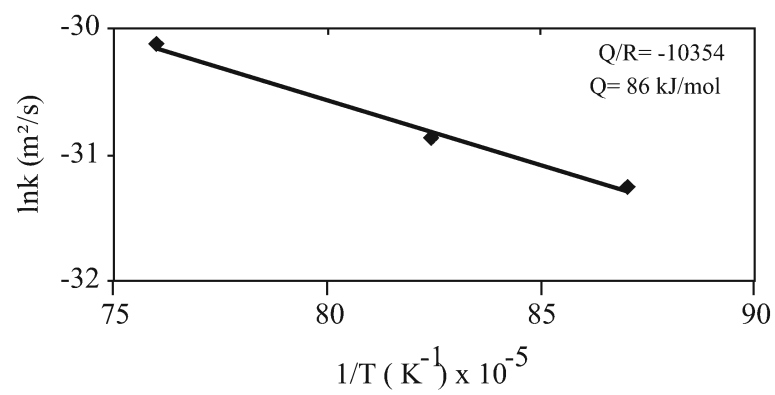

Fig. 6. Growth rate constant vs. inverse temperature of borided FeAl.

Table 2. Growth rate constants and activation energy of boriding on $\mathrm{FeAl}$ at $875^{\circ} \mathrm{C}, 940^{\circ} \mathrm{C}$ and $1040{ }^{\circ} \mathrm{C}$

Temperature Growth rate constant, $k$ Activation energy $\left(\begin{array}{lll}\left.{ }^{\circ} \mathrm{C}\right) & \left(\mathrm{m}^{2} \mathrm{~s}^{-1}\right) & \left(\mathrm{kJ} \mathrm{mol}^{-1}\right)\end{array}\right.$

\begin{tabular}{rlr}
875 & $2.65 \times 10^{-14}$ & \\
940 & $3.89 \times 10^{-14}$ & 86 \\
1040 & $8.16 \times 10^{-14}$ & \\
\hline
\end{tabular}

where $k_{0}$ is the frequency factor (pre-exponential constant), and $R\left(\mathrm{~J} \mathrm{~mol}^{-1} \mathrm{~K}\right)$ is the universal gas constant. Taking the natural logarithm of Eq. (2), Eq. (3) can be derived as follows:

$$
\ln k=\ln k_{0}-Q / R T .
$$

The squared layer thickness changes linearly with time as seen in Fig. 5. The values of $k$ were calculated from the slopes of the $x^{2}$ versus treatment time graphs for each boriding temperature.

Consequently, the activation energy for the boron diffusion in the boride layer is determined by the slope obtained by the plot ln $k$ vs. $1 / T$, using Eq. (3). The plot of $\ln k$ vs. reciprocal boriding temperature is thus shown in Fig. 6. Activation energy $(Q)$ was determined from the slopes of straight lines to the abscissa as the origin; the results are listed in Table 2. As we can see in Table 2 , the growth rate constant increases with the temperature.

\section{Discussion}

The SEM cross-sectional examinations showed three regions in Fig. 1. These are (1) a surface layer, consisting of $\mathrm{FeB}$ or $\mathrm{Fe}_{2} \mathrm{~B}$ phase, (2) a diffusion/transition zone, rich in boron, and (3) the substrate. Hardness measurements from the surface to the interior of the specimen revealed that the hardness of boride layer is much higher than of the matrix as seen in Figs. 2 and 3. Hardness of boride layer changes from 1290 to $1500 \mathrm{HV}$, whereas the hardness of the substrate varies from 340 to $490 \mathrm{HV}$ depending on treatment temperatures and times. The hardness of substrate dropped to value of $150 \mathrm{HV}$ for the sample boronized at $1040^{\circ} \mathrm{C}$ probably due to the grain growth of the sample exposed to high temperature for a long time during the boronizing process. The increase in hardness of boride layer is a consequence of the presence of hard $\mathrm{FeB}$ or $\mathrm{Fe}_{2} \mathrm{~B}$ as determined by $\mathrm{X}$-ray diffraction in Fig. $4 . \mathrm{Fe}_{2} \mathrm{~B}$ phase is formed at only $1040{ }^{\circ} \mathrm{C}$ for $8 \mathrm{~h}$. However, $\mathrm{FeB}$ phase is a major dominant phase at all boriding temperatures shown in Fig. $4 . \mathrm{Fe}_{2} \mathrm{O}_{3}$ phase is found at $1040{ }^{\circ} \mathrm{C}$ for $8 \mathrm{~h}$ boriding. The investigation in literature demonstrated that the samples boronized at $1000^{\circ} \mathrm{C}$ and $1050{ }^{\circ} \mathrm{C}$ for 12 and $15 \mathrm{~h}$ indicated the presence of $\mathrm{FeB}$ phase as well as $\mathrm{Fe}_{2} \mathrm{~B}$ phase [8]. This result is in agreement with the current study. The formation of single-phase $\mathrm{Fe}_{2} \mathrm{~B}$ or $\mathrm{FeB}$ or double phases $\mathrm{FeB} / \mathrm{Fe}_{2} \mathrm{~B}$ depends on the process temperature, chemical composition of substrate material, especially boron potential of medium and boriding time [23]. It can be claimed that because boron atoms diffuse into the boride layer towards the matrix, boron diffusion becomes increasingly difficult and the boron concentration at the surfaces increases, forming $\mathrm{FeB}$ phase due to its higher boron concentration than the $\mathrm{Fe}_{2} \mathrm{~B}$ phase. After the boride layer at the surface, the transition layer with the second hardness value is seen with the hardness ranged from 500 to $600 \mathrm{HV}$. The reason for higher hardness on the layer just below the boride layer (transition layer) is a result of a solid solution hardening between Fe and B. Then, the substrate, which is not affected from the boron dif- 
fusion, is observable with the nominal hardness value. It is observed from Fig. 5 that the longer the boriding time and the higher temperature, the greater the boride layer thickness is. The thickness of boride layer depends strongly on boriding time, the chemical composition of material to be borided, process temperature and the techniques such as gas, liquid and pack boriding. In this study, the chemical composition of material, and the technique are fixed; the only parameters that change are the boriding time and the temperature. Thus, the thickness of the boride layer changes with boriding time and increased temperature. Boride layers thickness ranged from 8 to $60 \mu \mathrm{m}$ with changing boriding temperatures and times. The kinetic behavior of the current study can be analyzed by the squared thickness increase with time in Fig. 6 . It is well known that there are two factors that control the overall reaction growth process for cases that combine reaction and diffusion. In other words, two consecutive steps, reaction and diffusion define the layer growth process. In the first, diffusion of atoms of reacting substances across the bulk of the material takes place in opposite directions. Subsequently, in the second step, chemical transformation takes place at the outer layer interfaces with the participation of diffusing atoms of one of the two components ( $\mathrm{B}$ in our case) and the surface atoms of the other component ( $\mathrm{Fe}$ atoms from $\mathrm{FeAl}$ ). The $\mathrm{B}$ atoms enter the reaction that exists at the surface of the $\mathrm{FeAl}$ while the Fe has to come from the mass of the substrate (FeAl) [24]. If the kinetics were controlled purely by reaction barriers, the boride layers would grow proportionally to time. If the kinetics were dominated by the diffusion-controlled mechanism, the square of boride layer would grow proportionally to the boriding time [7]. From that point, it is confirmed that the kinetics of the current study is diffusion-controlled process as seen in Fig. 5. The growth rates of the boronizing of $\mathrm{FeAl}$ increase with increasing temperature as shown in Table 2 and Fig. 6. This increase can be explained by Arrhenius-type equation given above. The movement of diffusing atoms ( $\mathrm{B}$ in our case) increases with temperature and diffusion becomes easier. Activation energy $Q$ was determined from the slopes of straight lines in Fig. 6. Activation energy is found to be $86 \mathrm{~kJ} \mathrm{~mol}^{-1}$. In one investigation performed on $\mathrm{Fe}_{72} \mathrm{Al}_{28}$ in slurry boriding medium, the activation energy was found to be $204 \mathrm{~kJ} \mathrm{~mol}^{-1}$ [8]. The difference between the current study and the literature can be attributable to different boriding process and conditions. In the current study, the solid pack boriding was used whereas boronizing was carried out in liquid bath consisting of borax and silicon carbide in the literature. The substrate of current study is different from the reported study. FeAl was used in the present study, whereas $\mathrm{Fe}_{72} \mathrm{Al}_{28}$ considered as $\mathrm{Fe}_{3} \mathrm{Al}$ was used in reported study. The use of different iron aluminides with dif- ferent aluminum content and different boron sources is believed to result in different activation energy. Apparently, the release of boron as an atom from the boron sources is much easier in the current study than that in reported study in the literature, causing much lower activation energy.

\section{Conclusions}

The following conclusions can be drawn from the present study:

(1) The boride formed on the iron aluminide has a type of saw-tooth shape.

(2) Examining X-ray analyses, FeB phase was seen as a major phase. However, $\mathrm{Fe}_{2} \mathrm{~B}$ phase was formed at only $1040^{\circ} \mathrm{C}$ for $8 \mathrm{~h}$.

(3) The microstructural studies show three distinct regions: (1) a surface layer consisting of boride FeB as a dominant phase at all temperatures, (2) the transition layer mostly composed of a solid solution with boride, which has a higher hardness value than the base metal and (3) base metal, which is not affected by boron.

(4) Depending on boronizing times and temperatures, the depth of borides formed on the surface of borided iron aluminide substrate ranges from 8 to $60 \mu \mathrm{m}$.

(5) The hardness of the boride on the substrate ranged from 1290 to $1500 \mathrm{HV}$ while the hardness of the substrate ranged from 340 to $490 \mathrm{HV}$ depending on treatment temperatures and times.

(6) Growth rate constant increases with temperature.

(7) Activation energy is found to be $86 \mathrm{~kJ} \mathrm{~mol}^{-1}$.

\section{Acknowledgements}

The authors would like to thank Mr. A. Sen for running the X-ray diffractometer, Mr. Ahmet Nazim for helping with SEM study, Mr. Ali Aydemir for helping with plotting at Gebze Institute of Technology, and Dr. Aytekin Polat for helping with experiment at University of Nigde.

\section{References}

[1] STOLOFF, N. S.: Materials Science and Engineering A, 258, 1998, p. 1. doi:10.1016/S0921-5093(98)00909-5

[2] NAKAMURA, R.-TAKASAWA, K.-YAMAZAKI, Y.-IIJIMA, Y.: Intermetallics, 10, 2002, p. 195. doi:10.1016/S0966-9795(01)00125-X

[3] LIU, C. T.-GEORGE, E. P.-MAZIASZ, P. J.SCHNEIBEL, J. H.: Materials Science and Engineering A, 258, 1998, p. 84 . doi:10.1016/S0921-5093(98)00921-6

[4] SLEBODA, T.-KANE, J.-WRIGHT, R. N.-STOLOFF, N. S.-DUQUETTE, D. J.: Materials Science 
and Engineering A, 368, 2004, p. 332. doi:10.1016/j.msea.2003.11.023

[5] BALASUBRAMANIAM, R.: Journal of Alloy and Compounds, 253-254, 1997, p. 148.

[6] SIKKA, V. K.-WILKENING, D.-LIEBETRAU, J.-MACKEY, B.: Materials Science and Engineering A, 258, 1998, p. 229. doi:10.1016/S0921-5093(98)00938-1

[7] EKMEKÇILER, E.-POLAT, A.-USTA, M.: Surface \& Coating Technology, 202, 2008, p. 6011.

[8] ÇELIKYUREK, I.-BAKSAN, B.-TORUN, O.GÜRLER, R.: Intermetallics, 14, 2006, p. 136.

[9] USTA, M.: Surface \& Coating Technology, 194, 2005, p. 251.

[10] USTA, M.-OZBEK, I.-IPEK, M.-BINDAL, C.UCISIK, A. H.: Surface \& Coating Technology, 194, 2005, p. 330. doi:10.1016/j.surfcoat.2004.06.042

[11] USTA, M.-OZBEK, I.-IPEK, M.-BINDAL, C.UCISIK, A. H.: Material Forum, 29, 2005, p. 65.

[12] INGOLE, S.-LIANG, H.-USTA, M.-BINDAL, C.-UCISIK, A. H.: Journal of ASTM International, 2, 2005, p. 1.

[13] INGOLE, S.-LIANG, H.-USTA, M.-BINDAL, C.-UCISIK, A. H.: Wear, 259, 2005, p. 849. doi:10.1016/j.wear.2004.12.024

[14] GENEL, K.-ÖZBEK, I.-KURT, A.-BINDAL, C.: Surface \& Coating Technology, 160, 2002, p. 38. doi:10.1016/S0257-8972(02)00400-0

[15] ERDEMIR, A.-BINDAL, C.: Surface \& Coating Technology, 76-77, 1995, p. 443.
[16] OZKAN, O.-USTA, M.-BINDAL, C.-UCISIK, A. H.: Vacuum, 80, 2006, p. 1391.

[17] SEN, S.-SEN, U.-BINDAL, C.: Surface \& Coating Technology, 191, 2005, p. 274. doi:10.1016/j.surfcoat.2004.03.040

[18] OZBEK, I.-BINDAL, C.: Surface \& Coating Technology, 154, 2002, p. 14. doi:10.1016/S0257-8972(01)01409-8

[19] UCISIK, A. H.-BINDAL, C.: Surface \& Coating Technology, 94-95, 1997, p. 561. doi:10.1016/S0257-8972(97)00466-0

[20] JAIN, V.-SUNDARARAJAN, G.: Surface \& Coating Technology, 149, 2002, p. 21. doi:10.1016/S0257-8972(01)01385-8

[21] GENEL, K.-OZBEK, I.-BINDAL, C.: Materials Science and Engineering A, 347, 2003, p. 311. doi:10.1016/S0921-5093(02)00607-X

[22] MELENDEZ, E.-CAMPOS, I.-ROCHA, E.-BARRON, M. A.: Materials Science and Engineering A, 234-236, 1997, p. 900. doi:10.1016/S0921-5093(97)00389-4

[23] USLU, I.-COMERT, H.-IPEK, M.-OZDEMIR, O.-BINDAL, C.: Materials \& Design, 28, 2007, p. 255.

[24] ANAStassiou, A.-CHRISTOGLOU, C.-ANGELOPOULOS, G. N.: Surface \& Coatings Technology, 204, 2010, p. 2240. doi:10.1016/j.surfcoat.2009.12.018 